\title{
Arachidonic acid 15-lipoxygenase and traces of E prostaglandins in purified human prostasomes
}

\author{
E. H. Oliw ${ }^{1}$, R. Fabiani ${ }^{2}$, L. Johansson ${ }^{3}$ and G. Ronquist ${ }^{2}$ \\ ${ }^{1}$ Department of Pharmaceutical Biosciences, Uppsala University Biomedical Center, Uppsala, Sweden; \\ ${ }^{2}$ Department of Clinical Chemistry; and ${ }^{3}$ Department of Obstetrics and Gynaecology, \\ Academic Hospital, Uppsala, Sweden
}

\begin{abstract}
Human spermatozoa are associated with arachidonate 15-lipoxygenase activity. This activity could be due to 15-lipoxygenase in small organelles (prostasomes), which are known to bind hydrophobically to germ cells. This possibility was assessed by separating prostasomes from human spermatozoa by differential centrifugation and purifying them by gel filtration (Sephadex G-200). Purified prostasomes metabolized $\left[\mathrm{I}^{14} \mathrm{C}\right]$ arachidonic acid to 15(S)-hydroxyeicosatetraenoic acid as determined by reverse phase and by chiral phase HPLC and by gas chromatography-mass spectrometry. Biosynthesis of prostaglandins could not be detected, but the prostasomes contained trace amounts of the four major E prostaglandins of human seminal fluid ( $3.6 \mathrm{nmol} \mathrm{mg}{ }^{-1}$ of prostasomal protein). Arachidonic acid 15-lipoxygenase has recently been implicated in the acrosome reaction of bull spermatozoa and it may have a similar function in the acrosome reaction of human spermatozoa.
\end{abstract}

\section{Introduction}

Prostasomes are small membrane organelles, which are secreted by the human prostate gland (Ronquist and Brody, 1985). A series of recent observations suggest that prostasomes may be important in human reproduction (Ronquist and Brody, 1985; Ronquist et al., 1990; Kelly, 1991). Prostasomes are known to bind hydrophobically to spermatozoa and they have been implicated in the immunosuppressive activity of seminal fluid and also in the motility of spermatozoa (Stegmayr and Ronquist, 1982; Kelly ef al., 1991). Human seminal plasma also contains large amounts of prostaglandin $\mathrm{E}$, which induce immunosuppression and improve both the motility of spermatozoa and their penetration ability (Kelly, 1978; Aitken and Kelly, 1985; Colon et al., 1986; Oliw and Johnsen 1988; Quayle et al., 1989).

Little is known about the enzymes of the prostasomes. Partly purified human spermatozoa contain a lipoxygenase that metabolizes arachidonic acid to $15(S)$-hydroxyeicosatetraenoic acid (15(S)-HETE) (Oliw and Sprecher, 1989). This enzyme is also detected in seminal fluid after vasectomy and in the almost cell-free and prostasome-containing pellet after differential centrifugation of normal seminal fluid (Ronquist and Brody, 1985; Oliw and Sprecher, 1989). These findings indicate that biosynthesis of $15(S)$-HETE is catalysed by enzymes of the prostasomes, but seminal fluid contains many different cells in addition to spermatozoa and the exact origin of the lipoxygenase activity is therefore uncertain. Arachidonate 15lipoxygenase is, for example, prominent in human eosinophils, reticulocytes and airway epithelial cells and present in leucocytes and monocytes (Ford-Hutchinson, 1991).

The presence of 15-lipoxygenase in prostasomes could be of physiological importance for several reasons. Arachidonate

Received 13 November 1992. 15-lipoxygenase has recently been implicated in the acrosome reaction of bull spermatozoa (Lax et al., 1990) and in the lysis of intracellular organelles (Kühn and Brash, 1990; Ford-Hutchinson 1991). Arachidonic acid and other polyunsaturated fatty acids are present in phospholipids of spermatozoa and these fatty acids can be liberated from phospholipids by phospholipase $A_{z^{\prime}}$ which is present in prostasomes and in human spermatozoa (Lindahl et al., 1987; Langlais et al., 1992). These fatty acids can then be oxygenated by lipoxygenases and by other enzymes.

The present study had two objectives: first, to determine whether prostasomes were significantly contaminated by $\mathrm{E}$ prostaglandins, which could contribute to the reported effects of prostasomes on the motility of spermatozoa; and second, to determine whether arachidonic acid 15-lipoxygenase was present in purified human prostasomes.

\section{Materials and Methods}

Arachidonic acid (99\%) was from Sigma (St Louis, MO) and $\left[{ }^{14} \mathrm{C}\right]$ arachidonic acid $\left(55 \mathrm{Ci} \mathrm{mol}^{-1}\right)$ was from Amersham International (Amersham). 15(S)-HETE and 15(S,R)-HETE were prepared as described by Oliw and Sprecher (1989). Sephadex G-200 was from Pharmacia AB (Uppsala) and Earle's balanced salts medium (EBSS) was from Sigma. Human albumin was from Kabi-Vitrum (Stockholm) and 17-phenyltetranor-PGE ${ }_{2}$ was from the Upjohn Co (Kalamazo, MI).

\section{Preparation of prostasomes}

Semen was obtained with consent from patients, who were referred to the fertility clinic for investigation. Samples were 
obtained by masturbation. After liquefaction (30-45 min at room temperature), the spermatozoa were sedimented by centrifugation $\left(1000 \mathrm{~g}, 20 \mathrm{~min}, 4^{\circ} \mathrm{C}\right.$ ) and the supernatant was again centrifuged ( $100000 \mathrm{~g}, 2 \mathrm{~h}, 4^{\circ} \mathrm{C}$ ). The high speed pellet was suspended in $0.5 \mathrm{ml}$ of Tris- $\mathrm{HCl}$ buffer $\left(30 \mathrm{mmol} \mathrm{l}^{-1}\right.$, $\mathrm{pH} \mathrm{7.6),} \mathrm{containing} 130 \mathrm{mmol} \mathrm{NaCl} \mathrm{l}^{-1}$. Suspensions of four different ejaculates were pooled and subjected to gel filtration (Sephadex G-200, $40 \mathrm{~cm} \times 1.2 \mathrm{~cm}, 4^{\circ} \mathrm{C}$ ). The column was eluted with the same buffer (flow $6 \mathrm{ml} \mathrm{h}^{-1}$ ) overnight and fractions of $1.5-2 \mathrm{ml}$ were collected. Aminopeptidase was assayed (Laurell et al., 1982) as an enzyme marker of prostasomes (Ronquist, 1988; Ronquist et al., 1988) and the turbid fractions, which contained this enzyme, were pooled $(6-9 \mathrm{ml})$ and designated purified prostasomes. As a control, purified prostasomes were also boiled for $3 \mathrm{~min}$ to inhibit enzyme activity. These prostasomes were denoted 'boiled prostasomes'.

\section{Incubations with arachidonic acid}

One part of purified prostasomes $(1-2 \mathrm{ml})$ was incubated with $\left[{ }^{14} \mathrm{C}\right.$ arachidonic acid $\left(1 \mu \mathrm{Ci} \mathrm{ml}^{-1}\right)$ and the rest with $0.2 \mathrm{mmol}$ arachidonic acid $1^{-1}$ for $30 \mathrm{~min}$ at $37^{\circ} \mathrm{C}$. The two incubations were either combined or analysed separately. The incubations were terminated by four volumes of ethanol and the precipitated proteins were removed by centrifugation. After extraction (Powell, 1980), 15-HETE was assayed by HPLC and gas chromatography-mass spectrometry (GC-MS). Reversed phase and chiral phase HPLC were performed as described (Oliw and Sprecher, 1989), using a photo diode array detector (Waters 991 set at $235 \mathrm{~nm}$ for detection of cis-trans conjugated hydroxy fatty acids) or detection by radioactivity monitoring, using liquid scintillation (Beckman LS 2800). GC-MS analysis was performed as described by Brodowsky et al. (1992). Protein was determined as described by Bradford (1976).

\section{Prostaglandin E of prostasomes}

Prostaglandin E of the prostasomes was assayed essentially as described by Oliw and Johnsen (1988). In brief, $0.5 \mathrm{ml}$ of purified prostasomes and the internal standard, 17-phenyltetranor-PGE $(1 \mu \mathrm{g})$, were mixed and treated with $0.5 \mathrm{ml}$ of $0.5{\mathrm{~mol} \mathrm{KOH}{ }^{-1}}^{-1}$ to convert PGE to PGB. After $15 \mathrm{~min}$ at room temperature, water was added and prostaglandins were extracted twice with ethyl acetate after acidification $\left(\mathrm{pH} \mathrm{3} ; 0.5 \mathrm{~mol} \mathrm{HCl}^{-1}\right)$. The PGB compounds were then analysed by HPLC on a stationary phase with $\beta$-cyclodextrin silica as described (Oliw and Johnsen, 1988) using UV detection (278 nm).

\section{Effects of prostasomes on motility of spermatozoa}

Spermatozoa were obtained after swim-up from semen of normospermic men, who were evaluated for in vitro fertilization. Briefly, motile spermatozoa were obtained by gently placing $0.2 \mathrm{ml}$ of semen under $0.5 \mathrm{ml}$ of EBSS, containing sodium pyruvate $\left(1 \mathrm{mmol} \mathrm{l} \mathrm{l}^{-1}\right)$, penicillin $\mathrm{G}\left(100 \mathrm{iu} \mathrm{ml}^{-1}\right)$ and either human serum albumin $\left(10 \mathrm{mg} \mathrm{ml}^{-1}\right.$ ) or an optimal concentration of prostasomes $\left(0.7-1 \mathrm{mg}\right.$ protein $\left.\mathrm{ml}^{-1}\right)$ or albumin and boiled prostasomes in plastic Falcon tubes.
The tubes were incubated for $1 \mathrm{~h}$ at $37^{\circ} \mathrm{C}$ under $5 \% \mathrm{CO}_{2}$. The upper layer of the medium $(0.25 \mathrm{ml})$ in the albumin and the prostasome groups was aspirated and the motility of spermatozoa was examined at $0,1,3,6$, and $22 \mathrm{~h}$ with a HTM semi-automated motility analyser using a $\mu$-cell chamber, depth $20 \mu \mathrm{m}$ (Hamilton Research Inc., Danvers, MA). At each time of measurement, 150-200 spermatozoa were recorded for monitoring of percentage motile spermatozoa $(n=5)$.

\section{Results}

\section{Arachidonate 15-lipoxygenase of prostasomes}

Purified prostasomes metabolized $\left[{ }^{14} \mathrm{C}\right]$ arachidonic acid to one polar metabolite (Fig. 1a). The radiolabelled material was associated with UV absorbing material, which showed a UV absorbance maximum at $235 \mathrm{~nm}$. Chiral HPLC (Fig. Ib) resolved this material after methylation into a major peak, which had the same elution volume as 15(S)-HETE methyl ester, and a minor peak with the elution volume of $15(R)$-HETE methyl ester (see Kühn et al., 1987; Oliw and Sprecher, 1989). The finding that the metabolite mainly consisted of the $S$ isomer excluded nonenzymatic formation by autoxidation.

After purification by chiral HPLC, the metabolite was analysed by $\mathrm{GC}-\mathrm{MS}$ as the $\mathrm{Me}_{3} \mathrm{Si}$ ether methyl ester derivative. The metabolite showed a signal at $\mathrm{m} / \mathrm{z} 225$, which is a prominent ion in the mass spectrum of 15 HETE, at the same retention time as authentic 15-HETE $\mathrm{Me}_{3} \mathrm{Si}$ ether methyl ester derivative ( $C$ value 21.3 ). Conclusive structural evidence was obtained by hydrogenation of the UV absorbing material $(235 \mathrm{~nm})$ with the retention time of I5-HETE from reversed phase HPLC of an incubation of arachidonic acid with prostasomes. The mass spectrum of $\mathrm{Me}_{3} \mathrm{Si}$ ether methyl ester derivative of the hydrogenated material (Fig. 1c) showed important signals at $\mathrm{m} / \mathrm{z} 399\left(\mathrm{M}^{+}-15\right.$, a weak signal), $383\left(\mathrm{M}^{+}-31\right), 367\left(\mathrm{M}^{+}-47\right)$, $343\left(\mathrm{M}^{+}-71\right.$, loss of $\left.\mathrm{C}(16)-\mathrm{C}(20)\right), 314,253$ (343-90, a weak signal $), 239,221,203,173\left(\left(\mathrm{CH}_{3}\right)_{3}-\mathrm{Si}-\mathrm{O}^{+}=\mathrm{CH}-\left(\mathrm{CH}_{2}\right)_{4}-\mathrm{CH}_{3}\right.$, base peak) and in the lower mass range 103,83 and 73. The hydrogenated biological compound and the hydrogenated 15(S)-HETE standard showed virtually identical mass spectra and had the same $C$ value (22.0). These results based on GC-MS and UV analysis and on chiral HPLC, showed that prostasomes contained arachidonate 15-lipoxygenase. The reaction catalysed by this enzyme is summarized (Fig. 2).

\section{Prostaglandin E of prostasomes}

$19(R)$-Hydroxy-PGE $19(R)$-hydroxy-PGE, $\mathrm{PGE}_{1}$ and $\mathrm{PGE}_{2}$ are the four major prostaglandins of human seminal fluid and occur at high concentrations (Kelly, 1978; Oliw and Johnsen 1988). Small amounts of these four compounds were present in three suspensions of purified prostasomes (from 12 ejaculates) and the 19-hydroxylated compounds dominated. The total content of the four $\mathrm{E}$ prostaglandins was $0.018 \pm 0.011$ (SD, $n=3$ ) $\mu \mathrm{mol}$ per preparation of prostasomes prepared from four ejaculates, which corresponded to $3.6 \pm 1.1 \mathrm{nmol} \mathrm{mg}{ }^{-1}$ prostasomal protein. These figures should be compared with the average total amount per ejaculate of the four $E$ prostaglandins 

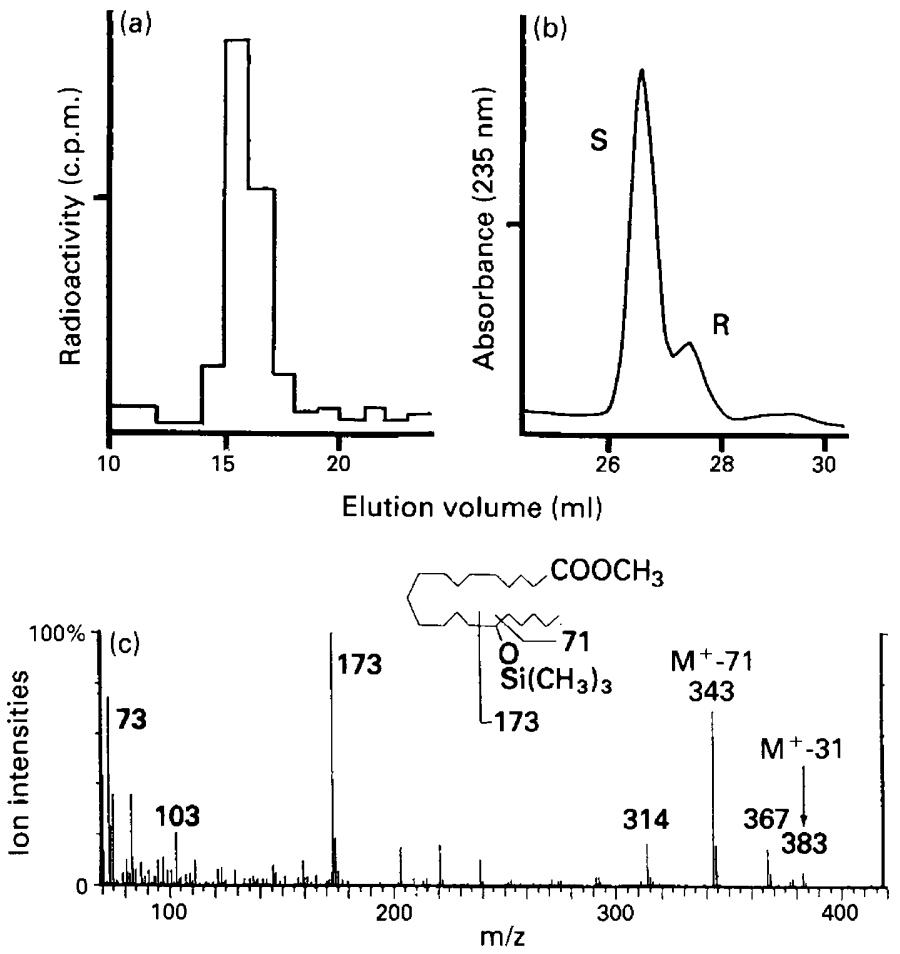

Fig. 1. (a) Reverse-phase HPLC of metabolites formed from ${ }^{14} \mathrm{C}$-labelled arachidonic acid by purified prostasomes. Partial chromatogram. (b) Partial separation of the $S$ and $R$ isomers of 15(S)-hydroxyeicosatetraenoic (15-HETE) methyl ester by chiral HPLC. (c) Mass spectrum of hydrogenated 15-HETE methyl ester. This compound was isolated from an incubation of prostasomes with arachidonic acid, purified by reversed phase HPLC and hydrogenated. $\mathrm{Me}_{3} \mathrm{Si}$ ether methyl ester derivative. Electron impact ionization.

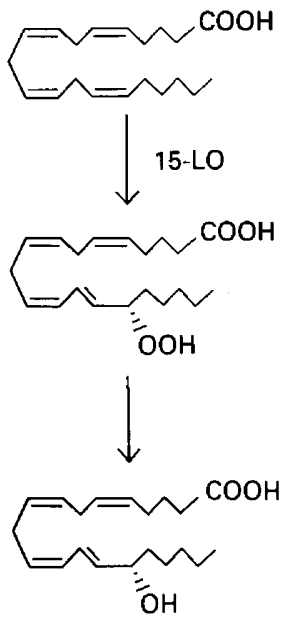

Fig 2. Summary of the biosynthesis of 15(S)-hydroxyeicosatetraenoic acid (15-(S)-HETE) from arachidonic acid in prostasomes. The hydroperoxide has not been isolated. 15-LO:15-lipoxygenase. in 40 normospermic men $(1.34 \pm 0.65 \mu \mathrm{mol})$ as determined by the same method (Oliw and Johnsen, 1988).

\section{Prostasomes and motility}

No significant difference in percentage of motile spermatozoa was observed among the three groups, which were treated with albumin, albumin and prostasomes, or albumin and boiled prostasomes, during the first $3 \mathrm{~h}$ of incubation (Fig. 3). However, spermatozoa incubated in a medium containing albumin and prostasomes showed a slight reduction in the number of motile spermatozoa after $6 \mathrm{~h}$ of incubation $(75 \pm 13 \%$; mean \pm SEM), while the motility of spermatozoa in the other two groups was unaffected (albumin with or without boiled prostasomes; $87 \pm 4 \%$ and $93 \pm 1 \%$, respectively). After $22 \mathrm{~h}$, spermatozoa incubated in the presence of albumin and prostasomes showed a dramatic reduction in motility ( $10 \pm 9 \%$ ) in comparison with spermatozoa incubated with albumin or with albumin and boiled prostasomes $(60 \pm 15 \%$ and $78 \pm 4 \%$, respectively). The difference in motility at $22 \mathrm{~h}$ was significant between the albumin-prostasome group and each of the other two groups $(P<0.05$; paired Student's $t$ test), whereas the difference between the two last groups was not significant. 


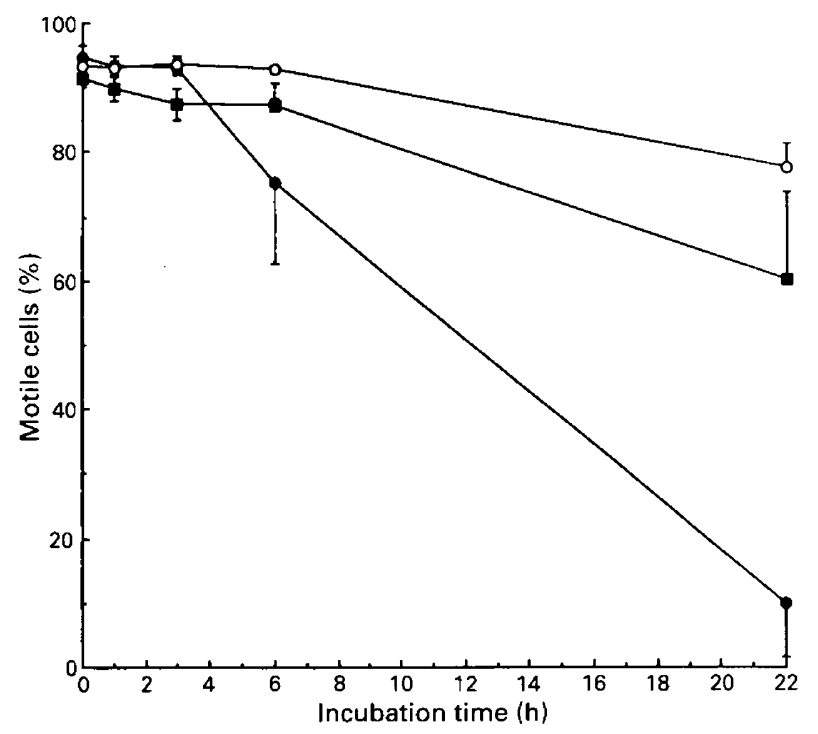

Fig. 3. Time curve for the effect of albumin ( $\mathbf{\square}$ ), albumin and prostasomes $(-)$ or albumin and boiled prostasomes $(O)$ on the percentage of swim-up spermatozoa with forward motility $(n=5$; mean \pm SEM).

\section{Discussion}

The study reported here shows that purified prostasomes possess arachidonate $15(S)$-lipoxygenase activity. This enzyme catalyses oxygenation at the $n-6$ carbon of many polyunsaturated fatty acids, leading to formation of a cis-trans conjugated hydroperoxy fatty acid, which is then reduced, enzymatically or nonenzymatically, to a conjugated hydroxy fatty acid. Our results strongly suggest that the arachidonate 15-lipoxygenase activity, which is associated with human spermatozoa, may be due to prostasomes. These organelles bind hydrophobically to spermatozoa (Ronquist et al., 1990), but additional 15lipoxygenase may, of course, be present in the spermatozoa or possibly in the other cells of the ejaculate.

The function of arachidonate 15-lipoxygenase in mammalian cells is unknown, but this enzyme has been implicated in the breakdown of intracellular organelles in reticulocytes (Kühn and Brash, 1990). In addition, arachidonate 15-lipoxygenase seems to be important in the acrosome reaction of bull spermatozoa (Lax et al., 1990). Polyunsaturated fatty acids and lipoxygenase products also seem to be important for the acrosome reaction of hamster spermatozoa (Meizel and Turner, 1983, 1984). It is possible that human prostasomes, which thus contain phospholipase $A_{2}$ as well as 15-lipoxygenase, may liberate arachidonic acid and generate 15-hydroperoxyeicosatetraenoic acid. The latter may initiate lipid peroxidation and a gradual increase in the fusogenic properties of the plasma membrane of the spermatozoa and, eventually, loss of membrane integrity, which may profoundly affect sperm function.

Many previous studies have shown that human spermatozoa lack cyclooxygenase (Kelly, 1978), whereas recent observations indicate that bovine spermatozoa could contain this enzyme (Shalev et al., 1992). In the present study the purified prostasomes were found to contain trace amounts of $\mathrm{PGE}_{1^{\prime}} \mathrm{PGE}_{2^{\prime}}$ 19-hydroxy-PGE ${ }_{1}$ and 19-hydroxy-PGE 2 . Seminal fluid contains very large amounts of these $\mathrm{E}$ prostaglandins. $\mathrm{PGE}_{1}$ and $\mathrm{PGE}_{2}$ are formed in the seminal vesicles by cyclooxygenase and they are then metabolized by cytochrome $\mathrm{P} 450$ of seminal vesicles to $19 R$-hydroxy-PGE ${ }_{1}$ and $19 R$-hydroxy-PGE 2 by $\omega 2-$ hydroxylation (Oliw et al., 1988). Previous studies have shown that human ejaculates contain $1.34 \pm 0.65 \mu \mathrm{mol}$ of the four major E prostaglandins, whereas purified prostasomes from four donors contained only $0.018 \mu \mathrm{mol}$ of $\mathrm{E}$ prostaglandins. The relative amounts of the four $\mathrm{E}$ prostaglandins of the prostasomes were similar to that of seminal fluid. It is therefore likely that they are derived from the seminal vesicles and are loosely bound to proteins of the prostasomes. Importantly, the amount of $\mathrm{E}$ prostaglandins of purified prostasomes is low and unlikely to affect spermatozoa motility and function significantly.

Prostasomes initially display a promotive effect on spermatozoa motility, but after incubation for $6 \mathrm{~h}$ the motility declined substantially. Boiled prostasomes did not show this negative effect on motility of spermatozoa at $6 \mathrm{~h}$, which suggested that some critical enzyme activity associated with the prostasomes was inactivated by heat. Accordingly, the decline in spermatozoa motility could be due to a general effect of prostasomes on the integrity of the plasma membrane of the spermatozoa (Ronquist et al., 1990; Lindahl et al., 1987). Disturbance of membrane integrity can lead to an influx of ions, which in high concentrations can be toxic to the spermatozoa. Another possibility is that some enzyme or enzymes associated with the prostasomes induce the acrosome reaction in the spermatozoa. Any of these events will eventually render the spermatozoa immotile. Further studies on the effect of prostasomes and inhibitors of prostasome-associated 15-lipoxygenase on the acrosome reaction of human spermatozoa will therefore be of physiological interest.

This work was supported by grants from the Swedish Medical Research Council (6523) and by Uppsala University.

\section{References}

Aitken RJ and Kelly RW (1985) Analysis of the direct effects of prostaglandins on human sperm function Journal of Reproduction and Fertility 73 139-146

Bradford MM (1976) A rapid and sensitive method for quantification of microgram quantities of protein utilizing the principle of protein-dye binding Analytical Biochemistry 72 248-254

Brodowski ID, Hamberg M and Oliw EH (1992) A linoleic acid (8R)-dioxygenase and hydroperoxide isomerase of the fungus Gaeumannomyces graminis Journal of Biological Chemistry 267 14738-14745

Colon JM, Ginsburg F, Lessing JB, Schoenfeld C, Goldsmith LT, Amelar RD, Dubin I and Weiss $G$ (1986) The effect of relaxin and prostaglandin $E_{2}$ on the motility of human spermatozoa Fertility and Sterility $461133-1139$

Ford-Hutchinson AW (1991) Arachidonate 15-lipoxygenase: characteristics and potential biological significance Eicosanoids 4 65-74

Kelly RW (1978) Prostaglandins in semen: their occurrence and possible physiological significance International joumal of Andrology 1 188-200

Kelly RW (1991) Seminal plasma immunosuppressive activity: the Achilles heel of reproduction International Journal of Andrology 14 243-247

Kelly RW, Holland P, Skibinski G, McMillan L, Hargreave T and James K (1991) Extracellular organelles (prostasomes) are immunosuppressive components of human semen Clinical and Experimental Immunology 85 550-556

Kühn H and Brash AR (1990) Occurrence of lipoxygenase products in membranes of rabbit reticulocytes Journal of Biological Chemistry 265 1454-1458

Kühn H, Wiesner R, Lankin VZ, Nekrasov A, Adler L and Schewe T (1987) Analysis of the stereochemistry of lipoxygenase-derived hydroxypolyenoic 
fatty acids by means of chiral phase high pressure liquid chromatography Analytical Biochemistry 160 24-34

Langlais J, Chafouleas JG, Ingraham R, Vigneault N and Roberts KD (1992) The phospholipase $A_{2}$ of human spermatozoa; purification and partial sequence Biochemical and Biophysical Research Communications 182 208-214

Laurell CB, Weber H, Ohlsson K and Rannevik G (1982) A zinc-dependent peptidase in prostatic organelles present in seminal plasma Clinica Chimica Acta 126 161-170

Lax Y, Grossman S, Rubinstein S, Magid N and Breitbart H (1990) The role of lipoxygenase in the mechanism of acrosome reaction in mammalian spermatozoa Biochimica et Biophysica Acta 1043 12-18

Lindahl M, Tagesson C and Ronquist G (1987) Phospholipase $A_{2}$ activity in prostasomes from human seminal plasma Urologia Internationalis 42 385-389

Meizel S and Turner KO (1983) Stimulation of an exocytotic event, the hamster sperm acrosome reaction, by cis-unsaturated fatty acids FEBS Letters 161 315-318

Meizel S and Turner KO (1984) The effect of products and inhibitors of arachidonic acid metabolism on the hamster sperm acrosome reaction Journal of Experimental Zoology 231 283-288

Oliw EH and Johnsen O (1988) Rapid and slow hydroxylators of seminal E prostaglandins Biochimica et Biophysica Acta 963 295-301

Oliw EH and Sprecher H (1989) Metabolism of polyunsaturated fatty acids by an (n-6)-lipoxygenase associated with human ejaculates Biochimica et Biophysica Acta 1002 283-291
Oliw EH, Kinn A-C and Kvist U (1988) Biochemical characterization of prostaglandin 19-hydroxylase of seminal vesicles Journal of Biological Chemistry $2637222-7227$

Powell WS (1980) Rapid extraction of oxygenated metabolites of arachidonic acid from biological samples using octadecylsilyl silica Prostaglandins 20 947-957

Quayle AJ, Kelly RW, Hargreave TB and James K (1989) Immunosuppression by seminal prostaglandins Clinical and Experimental Immunology 75 387-391

Ronquist G (1988) Zinc ion stimulation of ATP cleavage by prostasomes from human seminal plasma Urologia Internationalis 43 334-340

Ronquist G and Brody I (1985) The prostasome: its secretion and function in man Biochimica et Biophysica Acta 822 203-218

Ronquist G, Frithz G and Jansson A (1988) Prostasome membrane associated enzyme activities and semen parameters in men attending an infertility clinic Urologia Internationalis 43 133-138

Ronquist G, Nilsson BO and Hjertén S (1990) Interaction between prostasomes and spermatozoa from human semen Archives of Andrology 24 147-157

Shalev Y, Shemesh M, Marcus S, Rubenstein S and Breitbart H (1992) Localization of cyclooxygenase and production of prostaglandins in bovine sperm Biology of Reproduction 46 (Supplement 1) 149

Stegmayr B and Ronquist G (1982) Promotive effect on human sperm progressive motility by prostasomes Urological Research 10 253-257 